\title{
Emerging trend in the etiology of postpartum hemorrhage in a low resource setting.
}

\author{
Chigozie Ozoemena Ifeadike ${ }^{1}$, George Uchenna Eleje ${ }^{2,3^{*}}$, Ugochukwu Stanley Umeh ${ }^{3}$, Emmanuel \\ Ikechukwu Okaforcha ${ }^{3}$ \\ ${ }^{1}$ Department of Community Medicine, Faculty of Medicine, Nnamdi Azikiwe University, Nnewi, Anambra State, \\ Nigeria \\ ${ }^{2}$ Effective Care Research Unit, Department of Obstetrics and Gynecology, Faculty of Medicine, Nnamdi Azikiwe \\ University, Nnewi, Nigeria \\ ${ }^{3}$ Department of Obstetrics and Gynecology, Nnamdi Azikiwe University Teaching Hospital, Nnewi, Nigeria
}

\begin{abstract}
Background: While rates of postpartum hemorrhage (PPH) have continued to rise, it is not clear if the etiology and patterns have changed over time. Anecdotal reports have shown that, other than uterine atony, genital tract laceration is emerging as the chief causes of PPH.

Objectives: This was to determine the changing trend in the prevalence, causes and maternal mortality associated with PPH in a low resource setting.

Methods: A retrospective cohort study of all parturients that had PPH at Nnamdi Azikiwe University Teaching Hospital, Nnewi, Nigeria from January 1st, 2006 to December 31st, 2015 was conducted. Post-partum blood loss was calculated by estimating blood losses in graduated containers and in bed lines and gauze packs.

Results: During the period under review, a total of 10,502 deliveries were conducted, out of which 119 women were managed for PPH, giving a prevalence of $1.13 \%$. Sixty-nine $(58.0 \%)$ had primary PPH and $50(42.0 \%)$ had secondary PPH. The overall leading cause of PPH was retained product of conception in $51(42.9 \%)$ cases. The commonest cause of primary PPH was genital tract laceration in $24(34.8 \%)$ cases followed by uterine atony in $21(30.4 \%)$ cases. The leading cause of secondary PPH was retained products of conception in $37(74.0 \%)$ cases, whereas its least causes were uterine sub-involution and gestational trophoblastic diseases in $1(2.0 \%)$ patient each. There was a significant association between the types of PPH and their risk factors/causes (genital tract laceration, uterine atony, retained product of conception, endometritis and coagulopathy; $\mathbf{p}<\mathbf{0 . 0 5}$ for all). The majority of the cases of primary PPH (94.6\%) survived the condition and $5.4 \%$ died.

Conclusion: Genital tract laceration has emerged as commonest cause of primary PPH followed by uterine atony, while the leading cause of secondary PPH was retained products of conception. This new trend in etiology warrants further investigation in other regions.
\end{abstract}

Keywords: Postpartum hemorrhage, Uterine atony, Genital tract laceration, Retained products.

\section{Introduction}

Majority of births are anticipated to be straightforward and guarding the birthing process normal is indispensable for good maternity care $[1,2]$. However, every skilled birth attendant must be cognizant of and be prepared for complications that lurk the mother and/or child such as postpartum hemorrhage (PPH) [1]. PPH arises mainly from the failure of the uterus to contract after delivery, leading to blood loss of $\geq 500 \mathrm{~mL}$ in vaginal delivery, $\geq 1000 \mathrm{~mL}$ in cesarean section, or a substantial drop in hematocrit compared with the antepartum level; the conditions may occur in the first 24 hours after delivery (primary $\mathrm{PPH}$ ) or between 24 hours and 6 weeks after delivery (secondary PPH) [3-5].

PPH is an important obstetric emergency, a leading direct cause of maternal death in developing countries and results from problems during and immediately after the third stage of labor $[6,7]$. PPH is an unpredictable and rapid cause of maternal death worldwide, with two-thirds of women with PPH having no identifiable risk factors. When the severe PPH occurs, without treatment it can lead to obstetrics sequel of maternal mortality.

Previous reports indicate that uterine atony is responsible for about $70-90 \%$ of primary $\mathrm{PPH}$ [7]. Some other causes of primary PPH include: laceration of the birth canal, retained product of conception and coagulation disorders. For some time now, greater emphasis has been placed on uterine atony as the cause of PPH [6,7]. There has been a lot of evidence-based information and research on the prevention of uterine atony as a cause of PPH, with little or no attention to other causes [3-6]. While rates of PPH have continued to rise, it is not clear if the etiology and patterns have changed over time. Anecdotal 
reports have shown that, other than uterine atony, genital tract laceration and retained product of conceptions are now emerging as the chief causes of PPH. This therefore constitute a research gap on the emerging causes of PPH. Against this backdrop, this study is aimed at determining the changing trend in prevalence, causes and the maternal mortality associated with $\mathrm{PPH}$ in a low resource setting. This study will also enable us to determine the major causes/risk factors for $\mathrm{PPH}$ in this environment, so as to proffer solutions and recommendations where necessary.

\section{Materials and Methods}

\section{A study area}

This study was done at Nnamdi Azikiwe University Teaching Hospital (NAUTH), a tertiary Health institution located at old Oba-Nnewi road, Nnewi, Nnewi North LGA of Anambra State, South-east Nigeria. Nnewi is the second largest in Anambra State in Nigeria. NAUTH was established in 1988 and commissioned on 19th July 1991. It trains resident doctors, medical students, paramedical and nursing students. It also provides both specialized and comprehensive medical care to the state and its environs.

The Obstetrics and Gynecology Department of Nnamdi Azikiwe University Teaching Hospital constitutes the following; Gynecology clinics and ward, Obstetrics/ante natal clinics, the labor ward, ultra sound room, lying-in ward, prenatal ward, labor ward theatre and special care baby unit.

\section{Study design}

This was a retrospective cohort study.

\section{Study population}

The study population included women, who had PPH at NAUTH from January 1st, 2006 to December 31st, 2015. In the hospital, women were managed for their labor events and any development of abnormality in labor was detected by the instituted partograph and was treated in accordance with standard obstetrics intervention(s) as deemed appropriate for each situation. The only indication for episiotomy was impending or threatening spontaneous perineal tears.

\section{Inclusion criteria}

Women that had PPH and delivered at NAUTH, Nnewi, Nigeria and those who were referred to the study hospital with a diagnosis of PPH during the period under review. In the study center, PPH is usually diagnosed by visual quantification of blood loss, measurement in containers, and estimation of losses in gauze packs and by hemodynamic instability of the patients.

\section{Exclusion criteria}

Parturients who had incomplete clinical data were excluded.

\section{Research instrument}

A checklist was designed to record the patients' profile, which included; age, marital status, highest educational qualification, occupation, parity, booking status, type of PPH (Primary or Secondary), risk factors/causes of $\mathrm{PPH}$, interventions done to control bleeding and outcomes/complications of PPH.

\section{Data collection}

A thorough scrutiny of the labor and delivery records of the obstetrics unit and the medical records department of the hospital was done to identify these patients. Their case files were retrieved and studied, data was extracted using a checklist. The NAUTH death register was also used to identify patients who died from $\mathrm{PPH}$ during the period under review.

\section{Data analysis}

Data analysis was done using SPSS version 20 software package. The patients were grouped into different ages, educational qualifications, marital status, occupations and parity. Patients who had College of education, Polytechnic and University qualifications as well as M.Sc and $\mathrm{PhD}$ were grouped as "Tertiary". In occupation, patients grouped as "others" included seamstresses, hair dressers and artisans, while house wives and students were classified as "Unemployed". Frequencies were calculated, and chi square was used to test for statistical significance with $p$ value $<0.05$. Results were presented using tables and charts.

\section{Ethical considerations}

Permission and approval were obtained from the Nnamdi Azikiwe University Teaching Hospital Ethics Committee. Information obtained from the case files was kept confidential and excluded patient's name or any detail that could lead to their identification.

\section{Results}

During the period under review, a total of 10,502 deliveries were conducted at NAUTH, out of which 119 women were managed for $\mathrm{PPH}$, giving a prevalence of $1.13 \%$. Only $37 / 119$ $(31.1 \%)$ of the patients were booked cases, whereas the majority $82 / 119(68.9 \%)$ were referred from centers such as maternity homes, private hospitals, primary health care centers, traditional birth attendants and even patients who delivered at home etc.

The socio-demographic status of the women is shown in Table 1. The mean age of the patients was 30.2 years (19-45 years). All the women had at least a primary school education. Majority $48(40.3 \%)$ of the patients were grand multiparous women (Para $\geq 5)$, while only $25(21.0 \%)$ were primipara (Para=1). There was a significant association between the patient's parity and type of $\mathrm{PPH}$ (multiparity; $\mathrm{P}=0.037$ ). The distribution of patients who had PPH according to their parity 
Citation: Ifeadike CO, Eleje GU, Umeh US, et al.. Emerging trend in the etiology of postpartum hemorrhage in a low resource setting. J Preg

is shown in Table 2. Sixty-nine $(58.0 \%)$ had primary PPH and $50(42.0 \%)$ had secondary PPH as shown in Table 2.

Table 1. Socio-Demographic data of the patients.

\begin{tabular}{|l|l|l|}
\hline & Frequency & Percentage (\%) \\
\hline Age & & \\
\hline$<20$ Years & 1 & 0.8 \\
\hline $20-29$ Years & 53 & 44.5 \\
\hline $30-39$ Years & 61 & 51.3 \\
\hline$\geq 40$ Years & 4 & 3.4 \\
\hline Educational Status & & \\
\hline Primary School & 19 & 16 \\
\hline Secondary School & 77 & 64.7 \\
\hline Tertiary & 23 & 19.3 \\
\hline Marital Status & & 31.1 \\
\hline Single & 116 & 47.5 \\
\hline Married & 2 & 0.8 \\
\hline Widowed & 56 & \\
\hline Occupation & & 1.7 \\
\hline Unemployed & & \\
\hline Trader & & \\
\hline
\end{tabular}

\begin{tabular}{|l|l|l|}
\hline Civil Servant & 17 & 14.3 \\
\hline Others & 9 & 7.6 \\
\hline Parity & & \\
\hline Primipara (1) & 25 & 21 \\
\hline Multipara (2-4) & 46 & 38.7 \\
\hline Grand Multipara ( $\geq 5)$ & 48 & 40.3 \\
\hline Total & 119 & 100 \\
\hline
\end{tabular}

Table 2. Relationship between the types of postpartum hemorrhage and parity of the patients.

\begin{tabular}{|l|l|l|l|l|l|}
\hline \multicolumn{7}{|c|}{ Type of postpartum hemorrhage } \\
\hline Parity & $\begin{array}{l}\text { Primary } \\
\text { PPH }\end{array}$ & $\begin{array}{l}\text { Secondar } \\
\text { y PPH }\end{array}$ & Total & $\begin{array}{l}\text { Percentag } \\
\text { e (\%) }\end{array}$ & P-value \\
\hline & $\begin{array}{l}\text { Frequency } \\
(\%)\end{array}$ & $\begin{array}{l}\text { Frequenc } \\
\text { y (\%) }\end{array}$ & & & \\
\hline Primipara (1) & $18(26.1)$ & $7(14.0)$ & 25 & 21 & 0.171 \\
\hline Multipara (2-4) & $21(30.4)$ & $25(50.0)$ & 46 & 38.7 & $* 0.037$ \\
\hline $\begin{array}{l}\text { Grand MultiPara } \\
\text { ( } \mathbf{5} \text { 5) }\end{array}$ & $30(43.5)$ & $18(36.0)$ & 48 & 40.3 & 0.453 \\
\hline Total & $\mathbf{6 9 ( 5 8 . 0 )}$ & $\mathbf{5 0 ( 4 2 . 0 )}$ & $\mathbf{1 1 9}$ & 100 & \\
\hline
\end{tabular}

The distribution of patients who had PPH by their risk factors/ causes of the PPH is depicted in Table 3.

Table 3. Relationship between the types of postpartum hemorrhage and the risk factors.

\begin{tabular}{|c|c|c|c|c|c|c|}
\hline \multicolumn{7}{|c|}{ Types of Postpartum Hemorrhage } \\
\hline $\begin{array}{l}\text { Risk Factors/ Causes } \\
\text { of PPH }\end{array}$ & Primary PPH & & Secondary PPH & & Total & \\
\hline & Frequency & Percentage (\%) & Frequency & Percentage (\%) & Frequency (\%) & P-value \\
\hline Genital Laceration & 24 & 34.8 & 4 & 8 & $28(23.5)$ & ${ }^{*}<0.001$ \\
\hline Uterine Atony & 21 & 30.4 & 1 & 2 & $22(18.5)$ & ${ }^{*}<0.001$ \\
\hline RPOC & 14 & 20.3 & 37 & 74 & $51(42.9)$ & ${ }^{*}<0.001$ \\
\hline ERBD & 0 & 0 & 2 & 4 & $2(1.7)$ & $<0.174$ \\
\hline GTD & 0 & 0 & 1 & 2 & $1(0.8)$ & 0.420 \\
\hline Endometritis & 0 & 0 & 5 & 10 & $5(4.2)$ & ${ }^{*}<0.012$ \\
\hline APH & 1 & 1.4 & 0 & 0 & $1(0.8)$ & 1.000 \\
\hline Coagulopathy & 5 & 7.2 & 0 & 0 & $5(4.2)$ & ${ }^{*}<0.073$ \\
\hline Uterine Rupture & 3 & 4.3 & 0 & 0 & $3(2.5)$ & 0.263 \\
\hline Pre-eclampsia & 1 & 1.4 & 0 & 0 & $1(0.8)$ & 1.000 \\
\hline Total & 69 & 100 & 50 & 100 & $119(100.0)$ & \\
\hline
\end{tabular}

The overall leading cause of PPH was retained placenta (RPOC) in $51(43 \%)$. The commonest cause of primary PPH was genital tract laceration in $24(34.8 \%)$ followed by uterine atony in $21(30.4 \%)$. The leading cause of secondary PPH was
RPOC in $37(74 \%)$ of cases, whereas its least causes were uterine atony and gestational trophoblastic diseases in $1(2 \%)$ patient each. There was a significant association between the types of $\mathrm{PPH}$ and their risk factors/causes (genital tract 
laceration, uterine atony, retained product of conception, endometritis and coagulopathy; $\mathrm{p}<0.05$ for all).

The Table 4 shows the distribution of patients who had PPH by the interventions done to arrest bleeding. Uterine evacuation and antibiotics cover were the commonest intervention done, whereas WOMAN (world maternal antifibrinolytic trial; a randomized control trial using tranexamic acid) trial and use of Vitamin $\mathrm{K}$ were the least interventions done. However, 56 (47.1\%) and 37 (31.1\%) women received blood transfusion due to primary and secondary $\mathrm{PPH}$ respectively.

Table 4. Relationship between the types of postpartum hemorrhage and the interventions done.

\begin{tabular}{|c|c|c|c|c|c|c|}
\hline \multicolumn{7}{|c|}{ Type of postpartum hemorrhage } \\
\hline & Primary PPH & & Secondary PPH & & & \\
\hline Interventions done & Frequency & Percentage (\%) & Frequency & Percentage (\%) & Total & P-value \\
\hline Oxytocics & 19 & 27.5 & 2 & 4 & 21 & *0.001 \\
\hline Manual Removal of Placenta & 9 & 13 & 2 & 4 & 11 & 0.117 \\
\hline Uterine Evacuation/ Antibiotics & 4 & 5.8 & 38 & 76 & 42 & ${ }^{*}<0.001$ \\
\hline Oxytocics/ repair & 22 & 31.9 & 6 & 12 & 28 & *0.015 \\
\hline WOMAN Trial & 3 & 4.3 & 0 & 0 & 3 & 0.263 \\
\hline Oxytocics/ Vitamin K & 3 & 4.3 & 0 & 0 & 3 & 0.263 \\
\hline Hysterectomy & 9 & 13 & 2 & 4 & 11 & 0.117 \\
\hline Total & 69 & 100 & 50 & 100 & 119 & \\
\hline
\end{tabular}

Some of the interventions done in other to arrest hemorrhage include; the use of oxytocics, manual removal of placenta, uterine evacuation, and WOMAN trial. However, $11(9.2 \%)$ patients had hysterectomy when the attempts above failed and $93(78.2 \%)$ of the patients had blood transfusion. All patients with secondary PPH due to RPOC were given broad spectrum antibiotics prior to uterine evacuation. The association between the risk factors for $\mathrm{PPH}$ and the interventions done was statistically significant (oxytocics alone, uterine evacuation/ antibiotics, oxytocics and repair; $\mathrm{p}<0.05$ for all).

The Table 5 shows the distribution of patients who had PPH their outcomes or complications. Majority had no complications.

Table 5. Relationship between the types of postpartum hemorrhage and the outcomes/complications.

\begin{tabular}{|l|l|l|l|l|l|}
\hline \multicolumn{5}{|c|}{ Type of postpartum hemorrhage } \\
\hline $\begin{array}{l}\text { Outcomes/ } \\
\text { Complications }\end{array}$ & $\begin{array}{l}\text { Primary } \\
\text { PPH }\end{array}$ & $\begin{array}{l}\text { Secondar } \\
\text { y PPH }\end{array}$ & Total & $\begin{array}{l}\text { Percentage } \\
(\%)\end{array}$ & $\begin{array}{l}\text { P. } \\
\text { value }\end{array}$ \\
\hline & Frequency & $\begin{array}{l}\text { Frequenc } \\
\text { y }\end{array}$ & & & \\
\hline No complications & 45 & 28 & 73 & 61.3 & 0.344 \\
\hline Anemia & 1 & 3 & 4 & 3.4 & 0.308 \\
\hline $\begin{array}{l}\text { Acute } \\
\text { Failure }\end{array}$ & 2 & 1 & 3 & 2.5 & 1.000 \\
\hline Shock & 14 & 5 & 19 & 16 & 0.204 \\
\hline Sepsis & 0 & 9 & 9 & 7.5 & $*<0.001$ \\
\hline Death & 7 & 4 & 11 & 9.2 & 0.759 \\
\hline Total & $\mathbf{6 9}$ & $\mathbf{5 0}$ & $\mathbf{1 1 9}$ & $\mathbf{1 0 0}$ & \\
\hline
\end{tabular}

Amongst those who had complications, shock, sepsis and death were the most significant, while few patients had anemia and acute renal failure.

Hemorrhage was successfully arrested in $73(61.3 \%)$ of the patients without any further complications, however $19(15.9 \%)$ had shock, 9 (7.5\%) had sepsis, 4 (3.4\%) had anemia, $3(2.5 \%)$ had acute renal failure secondary to hypovolemia and $11(9.2 \%)$ of the patients died. The types of PPH significantly influenced the patients' outcome on sepsis $(\mathrm{p}<0.005)$. During the period under review, a total number of 117 women died in this center from pregnancy and its related complications; postpartum hemorrhage therefore contributed $9.4 \%$ of the maternal mortality.

\section{Discussion}

The prevalence of postpartum hemorrhage $(\mathrm{PPH})$ at Nnamdi Azikiwe University Teaching Hospital, Nnewi, Nigeria during the period under review was obtained to be $1.13 \%$. This is close to a prevalence of $1.68 \%$ obtained in a similar retrospective cohort study done at Ile-Ife, Nigeria [8,9]. Another study done at Karachi, Pakistan showed the prevalence of $1.74 \%$ [10]. However, our result was not in keeping with a similar study done at a tertiary hospital in Tanzania, which gave the prevalence of $8.9 \%$ and $16.2 \%$ diagnosed using visual estimation of blood loss (VEBL) and hematocrit change methods respectively [11]. Dar es Salaam, Tanzania, where this study was done has a projected population of 5,342,198 in 2016, with a population growth rate of 5.6 Percent per annum. It is the largest city in Tanzania and the third fastest growing city in Africa (Ninth fastest in the world) [12], compared to Nnewi with a projected population 477,688 in 2016 and a 
Citation: Ifeadike CO, Eleje GU, Umeh US, et al.. Emerging trend in the etiology of postpartum hemorrhage in a low resource setting. J Preg Neonatal Med 2018;2(2):34-40.

population growth rate of 2.21 percent per annum [13]. Dar es Salaam is thus about 11 times more populous than Nnewi and this is the most likely explanation for the higher prevalence of PPH obtained in their study as against ours. Also, the hematocrit change method for diagnosis of PPH is considered more accurate than visual estimation of blood loss. Studies have shown that caregivers consistently underestimate actual blood loss [9].

Most of the patients that were managed for PPH in this study were referred from centers such as maternity homes, traditional birth attendants, primary health care centers, prayer houses and even patients who delivered at home. Those patients who booked for ante natal services at our center but delivered elsewhere constituted a majority of the booked cases that had PPH. A pattern similar to this was also observed in a local study done at a teaching hospital in Nigeria [9]. However, in another study done at Pakistan, it was observed that all the cases of PPH recorded in their center during the period of study were all referred from other facilities outside the hospital. There were $92.3 \%$ cases referred from local hospitals and $7.7 \%$ cases referred from other teaching hospitals.

The number of patients in this study managed for secondary PPH was much more compared to studies done in Nigeria and other parts of the world $[9,10,14]$. This may be due to delays in seeking appropriate help from a referral tertiary facility.

In this study, parity was significantly influenced by the patients' age and occupation $(\mathrm{P}>0.05)$, but it had no association with their educational qualification and marital status. Majority of the women were grand multiparous (Para $\geq 5$ ); a wellknown cause of atony, which is the second leading cause of primary $\mathrm{PPH}$, as compared to primipara; the least cause of primary $\mathrm{PPH}$ in this study. A different trend was observed at Ile- Ife, Osun state, Nigeria where majority of their women who had PPH were multiparous (Para=2-4), followed by primips $($ Para $=1)$ and grand multiparous (Para $\geq 5)$ women who who were the least recorded to have PPH [8]. At Pakistan however, PPH was commonest amongst primips (Para=1) followed by grand multiparous (Para $\geq 5$ ), and then multiparous (Para=2-4) women in that order. It is worthy of note that each of these parity groups have some risk factors for PPH that are common to them, also the different risk factors determined what type of PPH (primary or secondary) that the patients had ( $\mathrm{P}>0.001)$; and whichever risk factor that is prevailing at any point in time will determine the parity group that had more PPH. Amongst the primiparas, genital tract laceration was a very significant cause of PPH. This is most probably due their narrowed birth canal which thus confers a higher risk for genital tract laceration and episiotomy extension.

Retained product of conception was the overall commonest cause of PPH in this study, the commonest cause of primary $\mathrm{PPH}$ was genital tract laceration in $24(34.8 \%)$ cases followed by uterine atony in $21(30.4 \%)$ cases. This high prevalence of PPH secondary genital tract laceration or retained product of conception may be related to the poor management of the third stage of labor at the facilities from which they were referred. The current concept in the management of third stage of labor is active management, which entails interventions designed to facilitate the delivery of placenta and prevent uterine atony $[3,5]$. Its components include administration of oxytocics, controlled cord traction and uterine massage after delivery of placenta [3,5]. Although more emphasis has been placed on interventions for active management of third stage of labor, an unskilled birth attendant may have little or no knowledge of the active management of third stage of labor, which may be the reason for high number of cases with retained product of conception and secondary postpartum hemorrhage in this study.

When the basic interventions aimed at arresting hemorrhage in this study failed, peripartum hysterectomy may be the last resort [15]. This is because, as shown in this study, $11(9.2 \%)$ had hysterectomy, $93(78.2 \%)$ of the patients were transfused with blood, and $11(9.2 \%)$ died, as compared to $2(1.79 \%)$ hysterectomies, $51(45.5 \%)$ cases of blood transfusion and 6 $(5.3 \%)$ deaths in a similar study [9]. The outcome of the patients in this study was significantly influenced by the type of PPH they had; those who had primary PPH were more likely to have shock, acute renal failure and death, whereas those who had secondary PPH were more likely to develop anemia and sepsis $(\mathrm{P}<0.05)$.

PPH accounted for $9.4 \%$ of the maternal mortality in this study and is closer to a rate of $6.67 \%$ obtained from a local study [9], whereas on the worldwide basis $\mathrm{PPH}$ is implicated in about $25 \%$ of maternal mortality, especially in the developing countries $[3,5]$. Our findings are not all encompassing, as it may not reflect the prevailing status in rural areas that are remote from tertiary facilities. Also, prompt and appropriate measures are always put in place at our center to prevent mortalities due to obstetrics hemorrhage and other common life-threatening emergencies.

Aside causing maternal mortality, PPH is also associated with maternal morbidities such as increased risk for blood transfusion and its attendant complications, acute renal failure due to hypovolemia, anemia, sepsis, shock etc. Other possible long-term complications which could not be obtained in this study include failure of lactation, secondary amenorrhea and infertility. These conditions, if they eventually develop will adversely affect the woman's quality of life postpartum.

Though, we recorded a lower maternal mortality accruing to PPH, compared to other studies [16-18] we can only infer that there was a reduction, but cannot absolutely state that the first target of the MDG 5 was attained in our center; more studies are needed to determine the exact overall rate of reduction in maternal mortality. More measures in the prevention as well as prompt and proper interventions to control $\mathrm{PPH}$ in the developing countries, will further improve our maternal mortality and morbidity index.

Our findings have some strength. First, this is the first study confirming that there is changing trend in the etiology of $\mathrm{PPH}$ in low resource settings. Second, this appears to be the first study in Africa on the emerging etiology of PPH. As a limitation of our study, this is a retrospective cohort study and some data could be missing for the analysis, due to non- 
availability of all the information or data needed from the patients' case files. Additionally, long term complications such as amenorrhea, infertility or fistula were not assessed in this present study.

\section{Conclusion}

This study has revealed that genital tract laceration has emerged as commonest cause of primary $\mathrm{PPH}$ followed by uterine atony, while the leading cause of secondary PPH was RPOC, whereas its least causes were uterine atony and gestational trophoblastic diseases. There was a significant association between the various types of PPH and their risk factors or associated causes. This new trend in etiology warrants further investigation in other regions. Based on findings from this study, it is recommended that all deliveries should be conducted by a skilled birth attendant and high-risk pregnancies should be managed by a specialist. This is necessary to avoid delays in reaching and assessing health facility. Primary health centers and maternity homes should be properly equipped with materials and trained personnel and should also be encouraged to refer cases promptly.

\section{Author contributions}

The study arose from an original idea from GUE and USU. All authors contributed to the study design. GUE, COI, USU, and EIO wrote the first draft, and COI, USU and CEN advised on the analysis. All authors contributed to the discussion, conclusion and review of the article.

\section{Conflicts of interest}

The authors declare that there is no conflict of interest.

\section{References}

1. Yildirim D, Ozyurek SE. Intramuscular oxytocin administration before vs. after placental delivery for the prevention of postpartum hemorrhage: A randomized controlled prospective trial. Eur J Obstet Gynecol Reprod Biol. 2018;224:47-51.

2. Egenberg S, Oian P, Eggebo TM, et al. Changes in selfefficacy, collective efficacy and patient outcome following interprofessionalsimulation training on postpartum haemorrhage. J Clin Nurs. 2017;26:3174-87.

3. Begley CM, Gyte GM, Devane D, et al. Active versus expectant management for women in the third stage of labour. Cochrane Database Syst Rev. 2015;2:CD007412.

4. Edwards HM. Aetiology and treatment of severe postpartum haemorrhage. Dan Med J. 2018;65.

5. Mousa HA, Blum J, Abou El Senoun G, et al. Treatment for primary postpartum haemorrhage. Cochrane Database Syst Rev. 2014;2:CD003249.

6. Ezeama CO, Eleje GU, Ezeama NN, et al. A Comparison of Prophylactic Intramuscular Ergometrine and Oxytocin for Women in the Third Stage of labor. Int J Gynaecol Obstet. 2014;124:67-71.
7. Ngwenya S. Postpartum hemorrhage: incidence, risk factors, and outcomes in a low-resource setting. Int J Womens Health. 2016;8:647-50.

8. Ononge $\mathrm{S}$, Mirembe $\mathrm{F}$, Wandabwa $\mathrm{J}$, et al. Incidence and risk factors for postpartum hemorrhage in Uganda. Reprod Health. 2016;13:38.

9. Ajenifuja KO, Adepiti CA, Ogunniyi SO. Postpartum haemorrhage in a teaching hospital in Nigeria: a 5-year experience. Afr Health Sci. 2010;10:71-4.

10. Muhammad MM, Hafiz MA, Zehra N, et al. Postpartum haemorrhage: Causes and management. BMC Research Notes. 2013;6:236.

11. Wangwe JT, Belinda B. Accuracy in diagnosis of postpartum haemorrhage using visual estimation of blood loss versus change in hematocrit in a tertiary teaching hospital in Tanzania. Tanzan J Health Res. 2012;14:1-9.

12. http://en.m.wikipedia.org/wiki/Dar_es_salaam. Accessed on 18th December, 2015.

13. http://en.m.wikipedia.org/wiki/nnewi. Accessed on 18th December, 2015.

14. Bateman BT, Berman MF, Riley LE, et al. The Epidemiology of Postpartum haemorrhage in a large nationwide sample of deliveries. Anesth Analg. 2010;110:1368-73.

15. Obiechina NJA, Eleje GU, Okeke CAF, et al. Emergency Peripartum Hysterectomy in Nnewi, Nigeria: A 10 -Year Review. Niger J Clin Pract. 2012;15:168-71.

16. Eleje GU, Igwegbe AO, Okonkwo JE, et al. Elderly Primigravida versus young primigravida: a review of pregnancy outcome in a low resource setting. Niger J Med. 2014;23:220-9.

17. Ezegwui HU, Onoh RC, Ikeako LC, et al. Investigating maternal mortality in a public Teaching Hospital, Abakaliki, Ebonyi State Nigeria. Ann Med Health Sci Res. 2013;3:75-80.

18. Gaym A. Maternal mortality studies in EthiopiaMagnitude, causes and Trends. Ethiop Med J. 2009;47:95-108.

\section{*Correspondence to}

George Uchenna Eleje

Department of Obstetrics and Gynecology

Nnamdi Azikiwe University

Nigeria

E-mail: gu.eleje@unizik.edu.ng 